\title{
Moderated online social therapy (MOST) for depression relapse prevention in young people: Pilot study of a 'next generation' online intervention
}

Simon Rice ${ }^{1,2^{*}}$, John Gleeson ${ }^{3}$, Christopher Davey ${ }^{1,2}$, Sarah Hetrick ${ }^{1}$, Alexandra Parker ${ }^{1}$, Reeva Lederman ${ }^{4}$, Greg Wadley ${ }^{4}$, Greg Murray ${ }^{5}$, Helen Herrman ${ }^{1}$, Richard Chambers ${ }^{6}$, Penni Russon $^{1}$, Christopher Miles ${ }^{1}$, Simon D’Alfonso ${ }^{1}$, Melissa Thurley ${ }^{2}$, Gina Chinnery ${ }^{1}$, Tamsyn Gilbertson ${ }^{1}$, Dina Eleftheriadis ${ }^{1}$, Emma Barlow ${ }^{1}$, Daniella Cagliarini ${ }^{1}$, Jia-Wern Toh $^{2}$, Stuart McAlpine $^{2}$, Peter Koval ${ }^{3}$, Sarah Bendall ${ }^{1}$, Jens Einar Jansen ${ }^{7}$, Matthew Hamilton ${ }^{1}$, Patrick McGorry $^{1}$, Mario Alvarez-Jimenez ${ }^{1}$

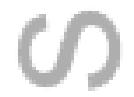

1. Orygen, The National Centre of Excellence in Youth Mental Health, The University of Melbourne

2. Orygen Youth Health, Melbourne

3. School of Psychology, Australian Catholic University

4. Department of Computing and Information Systems, The University of Melbourne

5. Department of Psychological Science, Swinburne University of Technology, Melbourne

6. Campus Community Division, Monash University, Melbourne

7. Psychiatric Research Unit, Psychiatry Region Zealand, Denmark 1

* Corresponding author: Dr Simon Rice; Orygen, The National Centre of Excellence in Youth Mental Health, The University of Melbourne, 35 Poplar Road, Parkville, Victoria, 3052, Australia; Phone: +613 9342 2942; Fax: +613 9342 2858; e-mail:

simon.rice@orygen.org.au

\section{Acknowledgements}

The authors acknowledge the HCF Foundation for providing funding for the study, and Orygen Youth Health (Youth Mood Clinic, Melbourne Health network) and headspace

This is the author manuscript accepted for publication and has undergone full peer review but has not been through the copyediting, typesetting, pagination and proofreading process, which may lead to differences between this version and the Version of Record. Please cite this article as doi: 10.1111/eip.12354

This article is protected by copyright. All rights reserved. 
Sunshine and headspace Glenroy for assisting with participant recruitment. Finally, the authors thank all participating young people for their involvement in the study.

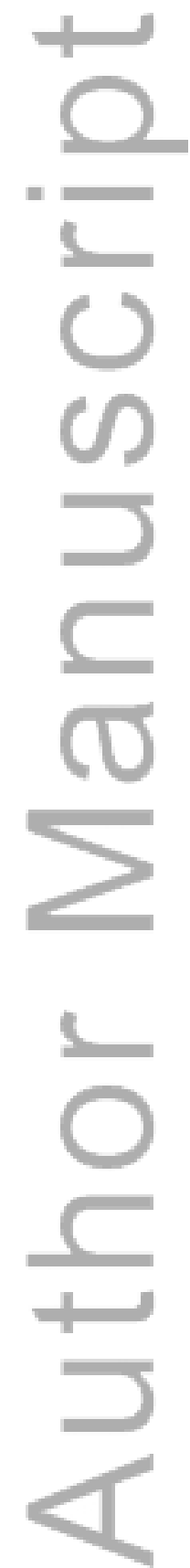

This article is protected by copyright. All rights reserved. 


\begin{abstract}
Aim: Implementation of targeted e-mental health interventions offer a promising solution to reducing the burden of disease associated with youth depression. A single group pilot study was conducted to evaluate the acceptability, feasibility, usability and safety, of a novel, moderated online social therapy (MOST) intervention (entitled Rebound), for depression relapse prevention in young people.

Methods: Participants were 42 young people ( $15-25$ years) (50\% male; mean age $=18.5$ years) in partial or full remission. Participants had access to the Rebound platform for at least 12-weeks, including the social networking, peer and clinical moderator, and therapy components.

Results: Follow-up data were available for 39 (92.9\%) participants. There was high system usage, with 3,034 user logins (mean=72.2 per user), and 2,146 posts (mean=51.1). Almost $70 \%$ of users had $\geq 10$ logins over the 12 -weeks, with $78.5 \%$ logging in over at least 2 -months of the pilot. A total of $32(84 \%)$ participants rated the intervention as helpful. There was significant improvement between the number of participants in full remission at baseline $(\mathrm{n}=5$; none of whom relapsed) relative to $\mathrm{n}=19$ at 12 -week follow-up $(p<.001)$. Six $(14.3 \%)$ participants relapsed to full threshold symptoms at 12-weeks. There was a significant improvement to interviewer rated depression scores (MADRS; $p=0.014, d=0.45$ ) and a trend for improved strengths use $(p=.088, d=0.29)$. The single-group design and 12-week treatment phase preclude a full understanding of the clinical benefits of the Rebound intervention.
\end{abstract}


Conclusions: The Rebound intervention was shown to be acceptable, feasible, highly usable and safe in young people with major depression.

Keywords: Depression; secondary prevention; recurrence; internet; adolescent

\section{INTRODUCTION}

It is estimated that as many as 1 in 4 young people will experience an episode of major depressive disorder by age $19 .^{(1,2)}$ Depression typically first manifests during adolescence or young adulthood (up to 25 years) ${ }^{(3)}$ and tends to display a worsening pattern over the course of repeated episodes, including a lack of responsiveness to initially effective treatments. ${ }^{(4)}$ Depression can be associated with significant distress and impairment for the individual and their family ${ }^{(5,6)}$ and may interrupt critical developmental phases ${ }^{(1)}$ resulting in long-term impairment and social exclusion/isolation. Depression is the leading cause of disability in developed countries, and is projected to be the leading cause of disability globally by $2030 .{ }^{(7)}$

Given the substantial social and economic costs associated with depressive disorders, effective early intervention, ${ }^{(8)}$ and maintenance of acute phase treatment effects is of critical importance. ${ }^{(9,10)}$ A recent Cochrane review of depression relapse prevention studies in young people, however, found little evidence to support any particular treatment approach in preventing relapse or recurrence of depressive episodes. ${ }^{(11)}$ Randomised controlled trials in young people have shown that medication is only modestly effective in preventing relapse of depression and improving functioning in the longer term, ${ }^{(12-14)}$ with meta-analyses casting doubt on the risk-benefit ratio of antidepressant use in those under 25 years in acute treatment ${ }^{(15,16)}$. Recent evidence suggests that targeted clinician-delivered psychological intervention, focusing on residual symptoms via a personal strengths and wellbeing 
framework significantly reduces risk of relapse in young people (as opposed to medication alone), ${ }^{(17)}$ though such face-to-face intervention is resource intensive and non-scalable. Given the increasing prevalence of depression, there is a clear need for the development of low cost programmes that are highly accessible and engaging. This is especially important given relapse presents a significant risk of impaired functioning (and relapse is less subject to external pressures over time), with the period of relapse risk extending far beyond typical treatment. Hence, there is a need to increase tenure of care in less intensive formats over the longer term. ${ }^{(18)}$

The recently developed World Health Organisation Mental Health Action Plan (2013$2020)^{(19)}$ calls for worldwide expansion of innovative community-based e-mental health interventions that make better use of mobile technologies, cohesive online professional and peer support, stepped care and engaging self-help. Such models enable people to initially engage in self- and peer-support, with access to more intensive help if needed. Within this framework, one of the most promising means of offsetting longer-term depression-related health burden among depressed young people is the development of engaging, innovative, online psychosocial interventions. ${ }^{(20)}$ Young people's enthusiasm for internet-based communication means that novel online interventions hold great promise for advancing longterm depression outcomes through the provision of engaging, acceptable, time-unlimited support. (21)

Due to their rapidly evolving nature, e-mental health interventions are expected to become increasingly appealing and available to young people over the next decade and beyond. ${ }^{(22)}$ Given their immediacy, 24-hour accessibility, and geographical scope, online interventions 
have potential to reach young people who may not be inclined or able to seek help from traditional sources. ${ }^{(23)}$ Many young people prefer online peer support over face-to-face interventions due to the stigma associated with mental illness, making online interventions a good alternative for those unlikely to engage in traditional treatment. ${ }^{(24)}$ Internet use has been shown to be effective in bolstering social support, which is known to protect against depression, ${ }^{(25)}$ with systematic reviews highlighting the effectiveness of online interventions for treating depression in young people. ${ }^{(26,27)}$ Nonetheless, attrition remains a significant issue for e-mental health interventions, ${ }^{(28)}$ with a substantial proportion of users dropping out in the early phase of treatment, ${ }^{(29)}$ with treatment completion rates ranging as low as $0.5 \%$ for depression-based interventions. ${ }^{(30)}$ Innovative solutions are required to better manage attrition in e-mental health interventions, and next-generation interventions are required for relapse prevention, including inbuilt real-time social networking peer support, ongoing engagement, responsive professional moderation and engaging self-help content. ${ }^{(27,31)}$

Social networking interventions enable people with a shared goal (i.e., improving symptom management, social functioning and connectedness) to help and support each other, share experiences and ask questions. ${ }^{(32,33)}$ The provision of peer support is thought to alter patterns of negative thinking and self-blame. ${ }^{(34)}$ A meta-analysis of peer support based interventions showed that peer support improves depression relative to usual care, with effects comparable to those seen for group-based cognitive behavioural interventions. ${ }^{(35)}$ More specifically in young people, recently published systematic reviews support the use of social networking enabled interventions for the management of high prevalence conditions such as depression $^{(36)}$ and suicide risk. ${ }^{(22)}$ 
While there is significant interest on the part of consumers for the opportunity to access online peer support for mental health concerns, ${ }^{(37)}$ evidence suggests that existing online interventions do not meet the specific needs of young people ${ }^{(38)}$ with few studies evaluating the effectiveness of peer support. ${ }^{(39)}$ Young people identify professional mental health practitioner involvement (i.e., non-automated), peer support and referral information as important intervention components that are currently missing from many online interventions. ${ }^{(38)}$ To our knowledge, there are currently no e-mental health social networking enabled interventions available for depression relapse prevention in young people. Such interventions are potentially important as peer support and social networking may enhance engagement with online interventions, proving useful in reducing mental health-related stigma, social isolation, and in addressing longer-term attrition and problems in maintenance treatment.

\section{Aims \& Hypotheses}

The Rebound pilot study was designed to evaluate the acceptability, feasibility, usability and safety of an innovative moderated online social therapy (MOST) for depression relapse prevention in young people. The Rebound intervention was expected to demonstrate acceptability, feasibility, usability and safety amongst the pilot cohort at conclusion of treatment (e.g., after 12-weeks of intervention participation). Acceptability and feasibility were evaluated via the number of logins to the system (i.e., with acceptability achieved if most participants logged on at least 10 times, over 2-months), in addition to favourable patterns of regular use of the system and perceived usefulness of the intervention. Usability was indicated by user ratings of the Rebound website ranking above the $50^{\text {th }}$ percentile 
against benchmarked commercially developed sites. Safety of the Rebound system was indicated by (i) participants reporting feeling adequately supported by moderators, measured via an end-of-treatment semi-structured interview; (ii) no unlawful entries into the Rebound system; (iii) all participants perceiving the system to be safe. Finally, indicative clinical benefit was assessed by improvements to depression remission rates, and interviewer-rated symptoms, between baseline and follow-up.

\section{METHODS}

\section{Participant recruitment}

A total of 103 referrals were received from practicing youth mental health clinicians from three participating early intervention clinics in Melbourne, Australia (the Youth Mood Clinic at Orygen Youth Health,, and two headspace centres in the Western suburbs of Melbourne). Following initial screening 27 referrals were deemed ineligible due to comorbidity, symptom severity, or lack of treatment response (see criteria below). In addition, $\mathrm{n}=18$ declined to participate, and $n=11$ were unable to be contacted. Following the full baseline interview a further $n=5$ referrals were deemed ineligible (based on severity of major depressive disorder; MDD). This resulted in $n=42$ eligible consenting participants who completed intervention induction and commenced the intervention.

\section{Inclusion, exclusion, and relapse criteria}

Broad inclusion criteria were adopted to reflect the clinical characteristics of young people with depression: (i) age of 15 to 24 years inclusive; (ii) a diagnosis of MDD using the Diagnostic and Statistical Manual of Mental Disorders (DSM-IV; Fourth Edition) criteria ${ }^{(40)}$ within the last 6 months; (iii) either partial remission for MDD (i.e., overall symptomatic 
improvement no longer meeting DSM-IV criteria but continuing to experience more than minimal symptoms) or full remission for MDD (i.e., asymptomatic for at least 2-months with no more than minimal symptoms); (iv) adequate response to specialised treatment for MDD, as assessed by a score of either 1 (very much improved) or 2 (much improved) on the Clinical Global Impression scale ${ }^{(41)}$ by the treating clinician; (v) no evidence of severe suicidality as assessed by a score of 4 or below on the suicidality item of the Brief Psychiatric Rating Scale $(\mathrm{BPRS}){ }^{(42)}$ for the month proceeding study entry; (vi) ability to give informed consent and comply with study procedures; (vii) regular and ongoing internet access. Participants meeting any of the following exclusion criteria were not approached for the Rebound pilot: (i) intellectual disability, (ii) inability to converse in, or read English, (iii) medical conditions requiring a high level of care, (iv) diagnosis of conduct, antisocial or borderline personality disorder from treating clinician.

\section{Design and Procedure}

Ethical approval for the project was received from the Melbourne Health Human Research Ethics Committee (Approval: 2013.276). The study utilised an uncontrolled single-group design. Study participants were recruited over a 6-month period (June 2014 - December 2014), with the treatment completion phase concluding at the end of March 2015. All participants were referred by treating clinicians, upon which the study research assistant (RA) conducted an initial eligibility screen. After participant informed consent (and parental consent for those $<18$ years) was obtained, and the baseline assessment completed, the RA undertook an induction session with each participant. The induction session included providing participants with unique login details, helping them set up and personalise their 
account (e.g., selecting a profile picture), orienting them to the Rebound system, and explaining the terms of use. Moderators welcomed new users and encouraged existing users to interact with them within 24 hours of enrolment.

Throughout the intervention phase Rebound was monitored daily (i.e. at least $2 \mathrm{~h}$ /day during week-days, and $1 \mathrm{~h}$ /day during weekends) by the clinical moderation team. The clinical moderation team comprised seven clinical psychologists and a clinical social worker. In addition, moderation of specific topics was also provided by an expert vocational worker and an expert in youth participation. Moderation integrity was ensured through a detailed moderation manual, and weekly group supervision sessions with senior clinical researchers (SR, MAJ, JG) from the research team. Participants were assessed at baseline and 12-weeks follow-up on outcomes described below.

\section{Intervention}

Rebound is based on the moderated online social therapy (MOST) model ${ }^{(21,43,44)}$ which uses a positive psychology, mindfulness and strengths-based intervention uniquely integrating: i) peer-to-peer online social networking; ii) individually tailored interactive psychosocial interventions; and (iii) involvement of expert mental health and peer moderators. Rebound was developed as a purpose-built online platform to supplement to traditional face-to-face interventions for major depressive disorder. Components of the Rebound intervention were refined and adapted from a similar intervention developed for long term recovery in first episode psychosis. ${ }^{(45)}$

The basis of the Rebound intervention has been developed over a five-year period using participatory design principles. ${ }^{(46,47)}$ Intervention design has been based on continual 
feedback and testing with focus groups of stakeholders (i.e., service consumers and their families, youth representatives and specialist youth mental health clinicians). The development of Rebound draws on an expansive multidisciplinary collaboration including clinical psychologists, psychiatrists, social workers, vocational and peer support experts, in addition to human-computer interaction researchers, software programmers, professional creative writers, artists, and graphic and web designers.

The design of Rebound was informed by recommendations and previous research targeting mechanisms of change (via positive psychology strengths-based interventions) for relapse prevention in young people. ${ }^{(17,48)}$ This includes interventions addressing residual symptoms ${ }^{(11)}$, improved social connectedness, ${ }^{(49,50)}$ and the enhancement of personal strengths, wellbeing and positive emotion, ${ }^{(48)}$ rather than simply addressing young people's symptoms and deficits. An action-oriented approach was used, through which participants identified, discussed and exercised key personal strengths to enhance self-efficacy, improve social functioning and reduce symptoms of depression. User character strengths were identified through an interactive online card-sort task, based on the positive psychology framework. ${ }^{(51)}$ The card-sort task enabled users to progress through animated descriptions of 24 character strengths ${ }^{(52)}$, enabling them to identify the five top strengths (e.g., creativity, humour, love of learning) that resonated most closely for them. Once selected, key strengths were then saved within the online platform, and clinical moderators could refer back to them, thereby reinforcing and encouraging users to put their key strengths into action.

The online social networking component of Rebound was designed to reinforce therapeutic content available within the intervention, promote ongoing engagement and bolster social 
support. Evidence-based therapeutic content within Rebound was designed to be flexible and user-driven, and could be completed as discrete brief Steps (i.e., material covering a single concept, each requiring approximately 20 minutes; see Table 1 for examples of therapeutic content). While moderators suggest relevant therapeutic content to users, users are free to explore all aspects of the site at their own pace, without a set order of completion. The 56 separate therapy Steps in Rebound target known risk factors for relapse of depression (i.e., rumination, substance misuse, self-criticism), as well as promoting wellbeing and social connectedness.

Embedded with the therapy content were over 400 unique behavioural experiments, ${ }^{(53)}$ referred to as Actions, whereby users employ the therapy content (and their key strengths) within the offline world, with the aim of bolstering adaptive coping repertoires. Actions enable users to apply mindfulness, self-compassion and personal strengths in real world situations specifically relevant to them (i.e., social context, school, work, alone). The use of context specific, action-based suggestions through online interventions has been recommended to increase practice and generalisation of skills to real life situations. ${ }^{(54)}$ The following excerpt from Rebound discusses a strength-based action for users to try: "Strengths are like muscles; the more you exercise them, the stronger they get. Use your strengths diary to count up how many times you used your strength this week, and try to beat it next week. It'll feel a bit weird and artificial at first (just like bike-riding and texting with your thumbs did at first), but once it becomes a habit to exercise your strengths the homework feeling will go away and you'll keep getting the benefits." 
The Rebound system and the MOST model have been specifically designed to ensure constant content flow between the therapy and social networking components. This design feature creates an online relapse prevention therapeutic milieu, where participants can engage in safe and supported self-disclosure, take positive interpersonal risks, gain new perspectives, and obtain encouragement and validation. ${ }^{(45)}$

The Rebound intervention also included a group-based structured problem solving intervention (referred to as Talk it $\mathrm{Out}$ ). This function used an evidence based problem solving framework. ${ }^{(55,56)}$ Offered solutions and users' experiences were saved, providing a database for participants to refer to throughout the intervention. Each proposed Talk it Out was moderated in a structured manualised manner, through an iterative process of problem definition, brainstorming solutions, identifying pros and cons, and summarising possible choices.

The peer and clinical moderation component of Rebound followed the 'supportive accountability' theory-driven model of online engagement, ${ }^{(57)}$ focusing on experienced, trustworthy and accountable peer and expert moderators. Peer moderators were trained and supported young people with a recent lived experience of mental ill health. Clinical moderators were experienced youth mental health clinicians. Clinical moderators ensured the safety of the Rebound site through daily monitoring, and developed a formulation based treatment approach (using available information) for each allocated user. The clinical moderation team was supported through weekly supervision meetings (90 minutes) and additional ad hoc supervision where required. Rebound also incorporated specialised software to assist with moderation and safety of the site (i.e., a log for secure communication 
between moderators, an auto-detect risk management system for identified key words, realtime usage statistics including a word-cloud for tracking most frequently posted terms).

\section{$\underline{\text { Insert Table } 1 \text { Here }}$}

\section{Materials}

Baseline and follow-up diagnosis of major depressive disorder were assessed via Structured Clinical Interview for DSM-IV (SCID; patient version). ${ }^{(65)}$ Symptom rating measures at baseline and follow-up included two interviewer administered measures: the MontgomeryAsberg Depression Rating Scale $\left(\mathrm{MADRS}^{(66)}\right)$, and the Social and Occupational Functioning Scale $\left(\right.$ SOFAS ${ }^{(67)}$ ). In addition, participants provided self-report data using the Strengths Use Scale ${ }^{(68)}$, the Penn State Worry Questionnaire, ${ }^{(69)}$ the Medical Outcomes Social Support Survey ${ }^{(70)}$ (to assess social connectedness), the 2-Way Social Support Scale ${ }^{(71)}$ (to assess social support) and the Anxiety Subscale taken from the Depression Anxiety Stress Scales. ${ }^{(72)}$ User experience of Rebound was assessed (by an independent report and benchmarking) via the Website Analysis and Measurement Inventory (WAMMI). ${ }^{(73)}$

All standardised scales reported satisfactory internal consistency (see Table 4 for Cronbach alpha coefficients). Participants also provided data at follow-up on their subjective experience of the Rebound platform. Quantitative ratings were made for items specifically designed for the present study assessing safety, helpfulness, and perceived benefits in relation to social connectedness and empowerment, in addition to moderation (see Table 3 for all items). Participants were also asked whether they would recommend Rebound to another young person with depression. 


\section{Statistical analysis}

Intervention acceptability, feasibility and safety were determined by frequency ratings and patterns of use (means and standard deviations). Initial treatment benefit (relapse rate) was evaluated through McNemar's $\chi^{2}$ test. This was used to determine the statistical significance of the change in number of participants in full remission at baseline, and full remission at 12week follow-up. Paired samples t-tests were conducted and within-group effect sizes reported for changes between baseline and follow-up clinical measures.

\section{RESULTS}

Of the 42 participants recruited, $7.1 \%(n=3)$ were lost to follow-up with $92.9 \%$ completing the 12-week follow-up assessment. The mean age at baseline was 18.5 years $(\mathrm{SD}=2.1)$ with $50.0 \%(\mathrm{n}=21)$ of participants male. All participants were unmarried, and no participants reported having children. A total of $95.2 \%(n=40)$ of participants were born in Australia, with $97.6 \%(n=41)$ of participants native English speakers. A total of $92.9 \%(n=39)$ lived with their family (i.e., parents or other relatives), while the remainder lived in rented accommodation. Most $(54.8 \%, \mathrm{n}=23)$ participants were not working, however $64.3 \%(\mathrm{n}=27)$ were studying full-time, $7.1 \%(n=3)$ were studying part-time, and $28.6 \%(n=12)$ identified as not studying. Clinician ratings on the Clinical Global Impression Scale ${ }^{(41)}$ at baseline indicated that $81.0 \%(\mathrm{n}=34)$ of participants were much improved, while the remaining $19 \%$ $(n=8)$ were very much improved in their clinical presentation since initial treatment commencement. On average, participants had been receiving mental health care for 12.21 months ( $\mathrm{SD}=11.07)$. At follow-up, 33.3\% $(\mathrm{n}=13)$ of participants had been discharged from 
clinical care. A total of $97.6 \%(n=41)$ reported general daily internet use. Most $(57.1 \%, n=24)$ estimated their daily internet use as $>4$ hours per day.

\section{Acceptability}

Acceptability was achieved if most participants logged on $\geq 10$ times, over 2-months of the pilot. A total of $66.7 \%(n=28)$ of users met this criteria. In addition, $60 \%(n=25)$ of participants utilised the system at least monthly over the 12-week intervention phase.

\section{Feasibility}

High system use was observed across the participants, with a total of 3034 system logins (see Table 2 for descriptive statistics). The social networking component (posts, comments, likes and contributions to Talk it Out's) was used by all 42 participants. Throughout the intervention there were 751 unique posts, with $50 \%(n=21)$ of users authoring $\geq 10$ posts. In addition there were 819 likes (where a user clicks the 'Like' function on another users post) with $40.5 \%(n=17)$ of users clicking $\geq 10$ 'likes', and 576 user generated comments with $31.0 \%(\mathrm{n}=13)$ authoring $\geq 10$ comments. A total of 19 distinct Talk it Out topics were proposed by $33.3 \%(n=14)$ of participants. In terms of therapeutic content, $42.9 \%(n=18)$ of users completed $\geq 5$ therapy steps, and $26.2 \%(n=11)$ of users completed $\geq 5$ behavioural experiments (referred to as actions).

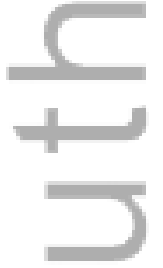

\section{Insert Table 2 Here}

Participants provided positive ratings of their experience with Rebound (see Table 3), rating the site favourably in terms of safety, user experience, and confidentiality. Mean ratings also 
indicated that participants experienced Rebound to be helpful for feeling more socially connected, and also for controlling their mood. All but one participant $(\mathrm{n}=37,97.4 \%)$ reported they would recommend Rebound to a young person experiencing depression. All ratings of self-report questions regarding moderation of Rebound were within the positive range (see Table 3).

\section{Usability}

Participant user experience data was collected via the WAMMI. ${ }^{(73)}$ The WAMMI is a standardised industry tool for benchmarking websites based on a propriety algorithm. ${ }^{(74,75)}$ WAMMI data was analysed independently by user experience researchers based at the University of Cork, Ireland. Reporting of the 5 WAMMI domains, and a global utility score (GUS), are expressed as percentiles. Based on mean values from 38 participant responses, the Rebound website scored above average on all five WAMMI domains of attractiveness 56.6 ( $\mathrm{SD}=27.3)$, controllability $61.5(\mathrm{SD}=24.8)$, efficiency $56.9(\mathrm{SD}=26.9)$, helpfulness 59.5 ( $\mathrm{SD}=22.7$ ), and learnability 65.5 ( $\mathrm{SD}=21.6)$, achieving a global usability score (GUS) percentile rank of $59.6(\mathrm{SD}=18.9)$. The WAMMI also includes a secondary analysis of GUS scores according to the relatively importance of the website to the user (i.e., 'How important for you is the kind of website you have just been rating'). Of the 38 respondents, $\mathrm{n}=9$ (23\%) rated Rebound as 'Extremely important' to them, with this group demonstrating a relatively high mean GUS=70.4. Thereafter, $\mathrm{n}=21(55 \%)$ rated the site as 'Important' with a mean GUS $=58.3, \mathrm{n}=7(18 \%)$ rated the site as 'Not very important' with a mean GUS=48.0, and $\mathrm{n}=1$ rated the site as "Not important at all', mean GUS=69.0. 


\section{Safety}

All participants reported feeling safe when using the Rebound intervention (see Table 3). No inappropriate usage of the system occurred throughout the intervention. There was one serious adverse event reported during the treatment phase, though this was unrelated to the intervention (suicide attempt, not requiring hospital admission). Importantly, analysis indicated no overall worsening of depression symptoms or functioning across the intervention phase (see Table 4). Similarly, there were no increased anxiety or worry as a result of using the system and interacting with other users.

\section{Insert Table 3 Here}

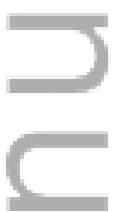

\section{Clinical variables}

Between baseline and follow-up there was a significant increase in the number of participants achieving full remission (i.e., no longer meeting DSM-IV criteria for MDD over the previous two months, based on clinical interview $\left.{ }^{(65)}\right)$. At baseline $n=5(11.9 \%)$ participants were in full remission for MDD, which increased to $n=19(45.2 \%)$ at 12-week follow-up, McNemar's $\chi^{2}$ $(1, N=39)=13.0, p<.001$. All five participants who were in full remission at baseline sustained their full remission through to 12-week follow-up. There were six (14.3\%) participants who experienced a relapse of threshold depression symptoms at 12-weeks. All remaining participants met criteria for either single episode $(n=5)$ or recurrent $(n=9)$ MDD in partial remission (i.e., some MDD symptoms present at follow-up, but either full criteria not met, or there was a period without any significant mood symptoms lasting less than 2 
months $\left.{ }^{(65)}\right)$. The overall improvement in remission rates was mirrored by significant improvement in interviewer rated MADRS scores, of small-moderate effect $(\mathrm{d}=0.45)$ (see Table 4).

Results also indicated no deterioration in social or occupational functioning as assessed by the SOFAS (see Table 4). On the self-report measures there was trend $(p<.10)$ observed for improved strengths use. There was no significant increase in social connectedness, or social support, and no significant improvement for self-reported worry or anxiety at follow-up.

\section{$\underline{\text { Insert Table } 4 \text { Here }}$}

\section{DISCUSSION}

\section{Principal Results}

Preliminary findings showed the Rebound intervention to be engaging, feasible, usable, and safe. In addition, favourable system usage statistics suggest that young people were willing to use Rebound, at least in the medium term, as part of their recovery from depression. The social networking aspect of the study was used most frequently. In Rebound, social networking provides the context for a broader therapeutic milieu, operating to both maintain participant engagement while introducing and reinforcing therapeutic content (i.e., mindfulness, self-compassion) with expert and peer support. The inclusion of social networking is a point of difference of the MOST theory-driven model, where social networking and therapy are in effect combined. The favourable system usage statistics are an important finding, given the high attrition rates known to plague many online 
interventions. ${ }^{(29)}$ Participants were almost unanimous in indicating that they would recommend Rebound to a fellow young person experiencing depression, and usability ratings demonstrated that the website performed well, relative to commercially developed sites. Highly favourable ratings were provided for the moderation component of the platform.

Changes to clinical variables were also observed and the trend for improved strengths use, and the maintenance of social and occupational functioning is encouraging. Given the single group design, these results must be interpreted with caution and require evaluation in a controlled study. That said, the present results compare favourably with remission rates observed in controlled studies of youth $\mathrm{MDD}^{(76)}$ where remission rates at 12-weeks are relatively low (i.e., 30-40\%) ${ }^{(77,78)}$, although differences in baseline participant characteristics are acknowledged. Nonetheless, based on the significant improvement in the remission rate for depression (and the maintenance of remission for those asymptomatic at baseline) the Rebound intervention may be beneficial in achieving and sustaining symptom improvement (i.e., relapse prevention) in young people. We note that there was no significant change to the rating scale assessments of social connectedness or social support. Given the social networking focus of the intervention, this was surprising. It may be that the rating scales used were not sensitive to support provided specifically in the online environment. Indeed favourable participant responses (i.e., mean and median ratings) to the specific question of whether Rebound helped users feel more socially connected would support this.

\section{Comparison with Prior Work}

To our knowledge, this is the first comprehensive online intervention for youth depression that incorporates real-time social networking, peer and clinical moderation and interactive 
therapy content. To date, no studies have evaluated online interventions for specifically reducing risk of depression relapse in young people. ${ }^{(36)}$ Previous research from un-moderated online forums has demonstrated that negatively focused user generated content can become contagious and adversely impact wellbeing and mood of other users. ${ }^{(79,80)}$ Using a moderated system such as Rebound, which focuses on a strengths-based approach, may improve depressive symptoms while simultaneously minimizing exposure to deficit focused content, which may otherwise increase the likelihood of adverse effects (i.e., user anxiety or worry).

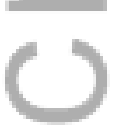

Comparable second generation e-mental health interventions for young people experiencing depression (i.e., those including some level of moderator or peer-support involvement) include the Bite Back positive psychology program, ${ }^{(81)}$ which used an asynchronous moderator-approved comment function, and the Master Your Mood intervention ${ }^{(82)}$ which used synchronous group chat facilitated by a clinician. These interventions have both demonstrated effectiveness in reducing depressive symptoms relative to a control condition. Similarly, the Problem Solving Therapy online intervention ${ }^{(83)}$ utilised asynchronous email feedback from clinicians to enhance problem-solving skills in depressed young people, and was found to be effective in comparison to a waitlist control condition. More recently, the

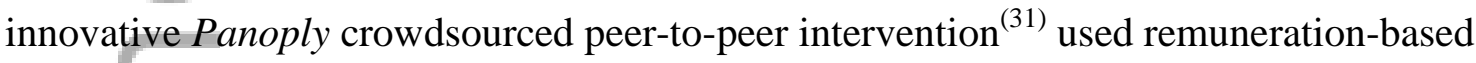
crowdsourcing (whereby non-clinicians are hired to review and respond to user posts related to stressful situations and negative automatic thoughts) in those aged 18 to 35 years. While Panoply was observed to improve depression scores over 3-weeks, the intervention group failed to differentiate from the control condition involving online expressive writing without feedback. Reporting of usage statistics in other studies makes it difficult to directly compare 
our findings (e.g., usage / logins over time). Regardless, the Rebound intervention is distinct and unique when compared to the above studies, in that it concurrently offers users 24-hour access to evidence-based content, and the possibility of using real-time social networking (i.e., where user generated is posted immediately to the network without moderator preapproval), embedded within ongoing input from supervised peer moderators.

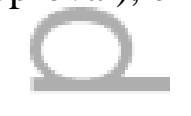

The most comparable intervention to the present study is the Horyzons pilot study. ${ }^{(45)}$ The Horyzons pilot also used the MOST model for relapse prevention, but recruited a sample of young people experiencing psychosis. Of note, the Horyzons pilot study reported a similar effect size as the present study did for change in depression, $(d=0.60)$ however, it was limited to a 4-week period. As in the present study however, the Horyzons pilot observed no significant change in self-reported anxiety. In sum, initial results from the Rebound intervention compare favourably with recent innovative e-mental health interventions for depression. Usage statistics (i.e., average, and median user logins) are either comparable, or exceed those established by previous similar studies. ${ }^{(45)}$

\section{Limitations and future directions}

The present study was designed to provide proof of concept by assessing feasibility, acceptability, usability and safety. Given this, the true clinical benefits and scope of Rebound remain unknown until a controlled evaluation can be undertaken, where participants have access to the intervention over a suitably longer duration of time e.g., $>12$ months. While the present study incorporated the use of a diagnostic interview and interviewer rated measures for depression and functioning, the single group design precluded the use of blinded 
assessments. Whilst reduction of symptoms does not demonstrate a direct benefit in terms of relapse prevention, it does provide promising data and warrants progress to a full randomised controlled trial focused on relapse prevention.

In order for the next generation of e-mental health interventions to be engaging and effective, an increasing amount of interactivity and support from peers and moderators will be required or possibly even expected by users. ${ }^{(36)}$ Embedding peer support within e-mental health interventions not only serves to meet recent global targets established within the WHO's Mental Health Action Plan, ${ }^{(19)}$ but also works to mobilise available community-based resources, decrease stigma and bolster adaptive coping. That said, greater interactivity between users, peer moderators and clinicians comes at a resourcing cost (i.e., to maintain the safety and fidelity of the intervention). It will be necessary for future generations of e-mental health interventions to carefully balance these costs, and include detailed economic evaluations evaluations.

Given moderation in part guides user interactions within online platforms, the moderation model of any online clinical intervention warrants attention. The present study has shown that a positive psychology strengths-based approach can be effectively implemented within an online platform. With the burgeoning popularity of online interventions, further articulation, development and refinement of online moderation models is needed to ensure interventions maintain longer-term treatment engagement, are undertaken with sufficient fidelity, and maximise the likelihood of effectiveness. Finally, it is suggested that future online intervention studies provide detailed temporal usage statistics. ${ }^{(84)}$ This should include the proportion of users being engaged over time, as well as frequency of usage. 


\section{Conclusions}

The Rebound pilot study demonstrated the MOST model of online intervention to be engaging, feasible, usable and safe for young people in recovery from depression. Favourable user feedback regarding intervention content, design and moderation, in addition to high overall usage rates, indicates the overall acceptability of the platform. While controlled evaluation is required to determine intervention efficacy and economic evaluations, initial results suggest possible treatment benefits in terms of reduced relapse rates and symptomology. In summary, the MOST model may be a promising longer term nextgeneration e-mental health intervention.

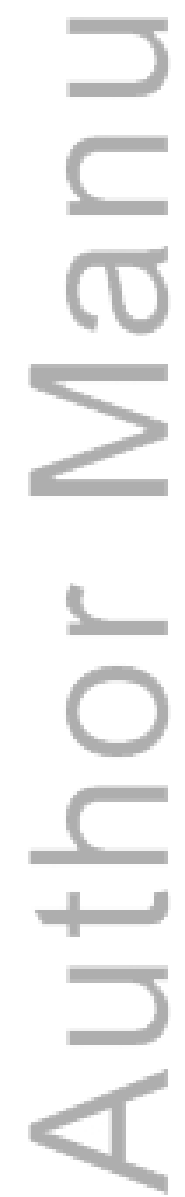




\section{Role of the funding source}

This study was generously supported by a research grant from the HCF Foundation. SR was supported via a Society for Mental Health Research Early Career Fellowship. MAJ was supported via the CR Roper Fellowship, Faculty of Medicine, Dentistry, and Health Science, the University of Melbourne and a Career Development Fellowship (APP1082934) by the National Health and Medical Research Council (NHMRC).

\section{Competing Interests}

The authors report no conflicts of interest for this research.

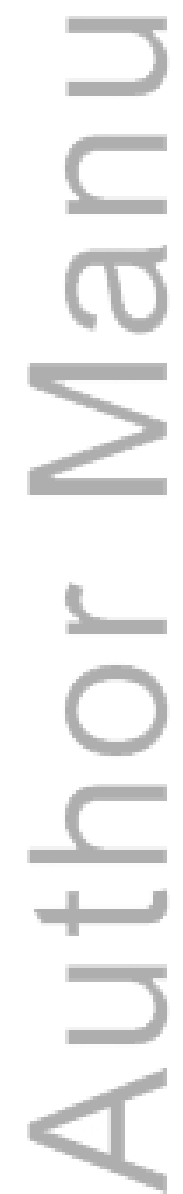

This article is protected by copyright. All rights reserved. 


\section{REFERENCES}

1. Lewinsohn PM, Rohde P, Seeley JR. Major depressive disorder in older adolescents: prevalence, risk factors, and clinical implications. Clinical Psychology Review. 1998;18(7):765-94, PMID: 9827321.

2. Rohde P, Lewinsohn PM, Klein DN, Seeley JR, Gau JM. Key characteristics of major depressive disorder occurring in childhood, adolescence, emerging adulthood, and adulthood. Clinical Psychological Science. 2013;1(1):41-53.

3. Kessler RC, Berglund P, Demler O, Jin R, Merikangas KR, Walters EE. Lifetime prevalence and age-of-onset distributions of DSM-IV disorders in the National Comorbidity Survey Replication. Archives of General Psychiatry. 2005;62(6):593-602, PMID: 15939837. 4. Kendler KS, Thornton LM, Gardner CO. Stressful life events and previous episodes in the etiology of major depression in women: an evaluation of the "kindling" hypothesis. American Journal of Psychiatry. 2000;157(8):1243-51, PMID: 10910786.

5. Brent DA, Poling KD, Goldstein TR. Treating depressed and suicidal adolescents: A clinician's guide: Guilford Press; 2011.

6. Quinn AL, Dean OM, Davey CG, Kerr M, Harrigan SM, Cotton SM, et al. Youth Depression Alleviation-Augmentation with an anti-inflammatory agent (YoDA-A): protocol and rationale for a placebo-controlled randomized trial of rosuvastatin and aspirin. Early Intervention in Psychiatry. 2015.

7. Mathers C, Fat DM, Boerma JT. The global burden of disease: 2004 update: World Health Organization; 2008.

8. Rice SM, Hickie IB, Yung AR, Mackinnon A, Berk M, Davey C, et al. Youth depression alleviation: the Fish Oil Youth Depression Study (YoDA-F): A randomized, double-blind, placebo-controlled treatment trial. Early Intervention in Psychiatry.

2014:PMID: 25130262.

9. Weisz JR, McCarty CA, Valeri SM. Effects of Psychotherapy for Depression in Children and Adolescents: A Meta-Analysis. Psychological Bulletin. 2006;132(1):132-49, PMID: 16435960.

10. Rice SM, Simmons MB, Bailey AP, Parker AG, Hetrick SE, Davey CG, et al. Development of practice principles for the management of ongoing suicidal ideation in young people diagnosed with major depressive disorder. SAGE Open Medicine. 2014;2:DOI: 2050312114559574.

11. Cox Georgina R, Fisher Caroline A, De Silva S, Phelan M, Akinwale Olaoluwa P, Simmons Magenta B, et al. Interventions for preventing relapse and recurrence of a depressive disorder in children and adolescents. Cochrane Database of Systematic Reviews. 2012;11:PMID: 23152246.

12. Cheung A, Kusumakar V, Kutcher S, Dubo E, Garland J, Weiss M, et al. Maintenance study for adolescent depression. Journal of Child and Adolescent Psychopharmacology. 2008;18(4):389-94, PMID: 18759650.

13. Emslie GJ, Heiligenstein JH, Hoog SL, Wagner KD, Findling RL, McCracken J, et al. Fluoxetine treatment for prevention of relapse of depression in children and adolescents: a double-blind, placebo-controlled study. Journal of the American Academy of Child \& Adolescent Psychiatry. 2004;43(11):1397-405, PMID: 15502599. 
14. Emslie GJ, Kennard BD, Mayes TL, Nightingale-Teresi J, Carmody T, Hughes CW, et al. Fluoxetine versus placebo in preventing relapse of major depression in children and adolescents. The American Journal of Psychiatry. 2008;165(4):459-67, PMID: 18281410. 15. Hetrick SE, McKenzie JE, Cox GR, Simmons MB, Merry SN. Newer generation antidepressants for depressive disorders in children and adolescents. The Cochrane Library. 2012:PMID: 23152227.

16. Bridge JA, Iyengar S, Salary CB, Barbe RP, Birmaher B, Pincus HA, et al. Clinical response and risk for reported suicidal ideation and suicide attempts in pediatric antidepressant treatment: a meta-analysis of randomized controlled trials. JAMA. 2007;297(15):1683-96, PMID: 17440145.

17. Kennard BD, Emslie GJ, Mayes TL, Nakonezny PA, Jones JM, Foxwell AA, et al. Sequential treatment with fluoxetine and relapse-prevention CBT to improve outcomes in pediatric depression. American Journal of Psychiatry. 2014;171(10):1083-90, PMID: 24935082.

18. Kreyenbuhl J, Nossel IR, Dixon LB. Disengagement from mental health treatment among individuals with schizophrenia and strategies for facilitating connections to care: a review of the literature. Schizophrenia Bulletin. 2009;35(4):696-7031, PMID: 19491314. 19. WHO. Comprehensive mental health action plan 2013-2020. Geneva: Sixty-sixth World Health Assembly2013.

20. Burns JM, et al. Game On: Exploring the Impact of Technologies on Young Men's Mental Health and Wellbeing. 2013 Young and Well Cooperative Reserach Centre 21. Alvarez-Jimenez M, Gleeson JF. Connecting the dots: Twenty-first century technologies to tackle twenty-first century challenges in early intervention. Australian and New Zealand Journal of Psychiatry. 2012;46(12):1194-6, PMID: 23212140.

22. Robinson J, Cox G, Bailey E, Hetrick S, Rodrigues M, Fisher S, et al. Social media and suicide prevention: a systematic review. Early intervention in psychiatry. 2015:PMID: 25702826.

23. Renton T, Tang H, Ennis N, Cusimano MD, Bhalerao S, Schweizer TA, et al. Webbased intervention programs for depression: a scoping review and evaluation. Journal of medical Internet research. 2014;16(9):e209, PMID: 25249003.

24. Gibson K, Cartwright C. Young people's experiences of mobile phone text counselling: Balancing connection and control. Children and Youth Services Review. 2014;43:96-104.

25. Bessière K, Pressman S, Kiesler S, Kraut R. Effects of internet use on health and depression: a longitudinal study. Journal of Medical Internet Research. 2010;12(1):e6, PMID: 20228047.

26. Davies EB, Morriss R, Glazebrook C. Computer-Delivered and Web-Based Interventions to Improve Depression, Anxiety, and Psychological Well-Being of University Students: A Systematic Review and Meta-Analysis. Journal of Medical Internet Research. 2014;16(5):e130, PMID: 24836465.

27. Farrer L, Gulliver A, Chan JK, Batterham PJ, Reynolds J, Calear A, et al. Technology-based interventions for mental health in tertiary students: systematic review. Journal of Medical Internet Research. 2013;15(5):e101, PMID: 23711740. 
28. Melville KM, Casey LM, Kavanagh DJ. Dropout from Internet-based treatment for psychological disorders. British Journal of Clinical Psychology. 2010;49(4):455-71, PMID: 19799804.

29. Eysenbach G. The law of attrition. Journal of medical Internet research. 2005;7(1):e11, PMID: 15829473.

30. Christensen H, Griffiths KM, Korten AE, Brittliffe K, Groves C. A comparison of changes in anxiety and depression symptoms of spontaneous users and trial participants of a cognitive behavior therapy website. Journal of Medical Internet Research. 2004;6(4):e46, PMID: 15631970.

31. Morris RR, Schueller SM, Picard RW. Efficacy of a Web-Based, Crowdsourced PeerTo-Peer Cognitive Reappraisal Platform for Depression: Randomized Controlled Trial. Journal of medical Internet research. 2015;17(3):e72, PMID: 25835472.

32. Mehta N, Atreja A. Online social support networks. International Review of Psychiatry. 2015(2):1-6, PMID: 25800079.

33. Eysenbach G, Powell J, Englesakis M, Rizo C, Stern A. Health related virtual communities and electronic support groups: systematic review of the effects of online peer to peer interactions. BMJ. 2004;328(7449):1166, PMID: 15142921.

34. Griffiths KM, Calear AL, Banfield M. Systematic review on Internet Support Groups (ISGs) and depression (1): Do ISGs reduce depressive symptoms? Journal of medical Internet research. 2009;11(3):e40, PMID: 19793719.

35. Pfeiffer PN, Heisler M, Piette JD, Rogers MA, Valenstein M. Efficacy of peer support interventions for depression: a meta-analysis. General hospital psychiatry. 2011;33(1):29-36, PMID: 21353125.

36. Rice SM, Goodall J, Hetrick SE, Parker AG, Gilbertson T, Amminger GP, et al. Online and social networking interventions for the treatment of depression in young people: a systematic review. Journal of medical Internet research. 2014;16(9):e206, PMID: 25226790.

37. Griffiths KM, Reynolds J, Vassallo S. An Online, Moderated Peer-to-Peer Support Bulletin Board for Depression: User-Perceived Advantages and Disadvantages. Journal of medical Internet research. 2015.

38. Wetterlin FM, Mar MY, Neilson EK, Werker GR, Krausz M. eMental Health Experiences and Expectations: A Survey of Youths' Web-Based Resource Preferences in Canada. Journal of medical Internet research. 2014;16(12):e293, PMID: 25519847.

39. Ali K, Farrer L, Gulliver A, Griffiths KM. Online Peer-to-Peer Support for Young People With Mental Health Problems: A Systematic Review. JMIR Mental Health. 2015;2(2):e19.

40. APA. Diagnostic and statistical manual of mental disorders, text revision (DSM-IVTR): American Psychiatric Association; 2000.

41. Guy W. Clinical global impression scale. The ECDEU Assessment Manual for Psychopharmacology-Revised Volume DHEW Publ No ADM 76. 1976;338:218-22.

42. Ventura J, Lukoff D, Nuechterlein K, Liberman R, Green M, Shaner A. Brief Psychiatric Rating Scale (Expanded Version 4.0). Los Angeles: UCLA Department of Psychiatry and Behavioural Sciences Clinical Research Center for Schizophrenia and Psychiatric Rehabilitation. 1993.

43. Gleeson J, Alvarez-Jimenez M, Lederman R. Moderated online social therapy for recovery from early psychosis. Psychiatric Services. 2012;63(7):719, PMID: 22752039. 
44. Lederman R, Wadley G, Gleeson J, Bendall S, Álvarez-Jiménez M. Moderated online social therapy: Designing and evaluating technology for mental health. ACM Transactions on Computer-Human Interaction (TOCHI). 2014;21(1):5.

45. Alvarez-Jimenez M, Bendall S, Lederman R, Wadley G, Chinnery G, Vargas S, et al. On the HORYZON: Moderated online social therapy for long-term recovery in first episode psychosis. Schizophrenia Research. 2013;143:143-9, PMID: 23146146.

46. Schuler D, Namioka A. Participatory design: Principles and practices: L. Erlbaum Associates Inc.; 1993.

47. Wadley G, Lederman R, Gleeson J, Alvarez-Jimenez M, editors. Participatory design of an online therapy for youth mental health. Proceedings of the 25th Australian ComputerHuman Interaction Conference: Augmentation, Application, Innovation, Collaboration; 2013: ACM.

48. Kennard BD, Stewart SM, Hughes JL, Jarrett RB, Emslie GJ. Developing cognitive behavioral therapy to prevent depressive relapse in youth. Cognitive and behavioral practice. 2008;15(4):387-99, PMID: 20535241.

49. Cruwys T, Haslam SA, Dingle GA, Haslam C, Jetten J. Depression and Social Identity: An Integrative Review. Personality and Social Psychology Review. 2014;18(3):21538, PMID: 24727974.

50. Cruwys T, South EI, Greenaway KH, Haslam SA. Social identity reduces depression by fostering positive attributions. Social Psychological and Personality Science. 2014: doi: $10.1177 / 1948550614543309$.

51. Peterson C, Seligman ME. Character strengths and virtues: A handbook and classification: Oxford University Press; 2004.

52. Park N, Peterson C, Seligman ME. Strengths of character and well-being. Journal of social and Clinical Psychology. 2004;23(5):603-19.

53. Rouf K, Fennell M, Westbrook D, Cooper M, Bennett-Levy J. Devising effective behavioural experiments. Oxford guide to behavioural experiments in cognitive therapy. 2004:21-58.

54. Van Gemert-Pijnen JE, Kelders SM, Bohlmeijer ET. Understanding the usage of content in a mental health intervention for depression: an analysis of log data. Journal of medical Internet research. 2014;16(1):e27.

55. McFarlane WR. Multifamily groups in the treatment of severe psychiatric disorders: Guilford Press; 2004.

56. McFarlane WR, Lukens E, Link B, Dushay R, Deakins SA, Newmark M, et al. Multiple-family groups and psychoeducation in the treatment of schizophrenia. Archives of General Psychiatry. 1995;52(8):679-87, PMID: 7632121.

57. Mohr DC, Cuijpers P, Lehman K. Supportive accountability: a model for providing human support to enhance adherence to eHealth interventions. Journal of medical Internet research. 2011;13(1):e30, PMID: 21393123.

58. Seligman ME, Rashid T, Parks AC. Positive psychotherapy. American psychologist. 2006;61(8):774-88, PMID: 17115810.

59. Rashid T, Ostermann RF. Strength-based assessment in clinical practice. Journal of clinical psychology. 2009;65(5):488-98, PMID: 19294732.

60. Seligman ME. Flourish: A visionary new understanding of happiness and well-being: Simon and Schuster; 2012. 
61. BBC. Make Yourself Happier Using Only A Pencil - Pleasure and Pain with Michael Mosley. Archived at: http://wwwwebcitationorg/6YAV2M4Xd, https://wwwyoutubecom/watch?v=MtV5kfH4IXs. 2011.

62. Neff K. Self-compassion: An alternative conceptualization of a healthy attitude toward oneself. Self and identity. 2003;2(2):85-101.

63. Bryant FB, Veroff J. Savoring: A new model of positive experience: Lawrence Erlbaum Associates Publishers; 2007.

64. Watkins ER. Constructive and unconstructive repetitive thought. Psychological bulletin. 2008;134(2):163-206, PMID: 18298268.

65. First MB, Spitzer RL, Gibbon M, Williams JB. Structured clinical interview for DSM-IV-TR axis I disorders, research version, patient edition. SCID-I/P, 2002.

66. = Montgomery SA, Asberg M. A new depression scale designed to be sensitive to change. The British journal of psychiatry. 1979;134(4):382-9, 444788.

67. Goldman HH, Skodol AE, Lave TR. Revising axis V for DSM-IV: a review of measures of social functioning. Am J Psychiatry. 1992;149(9):1148-56, PMID: 1386964.

68. Wood AM, Linley PA, Maltby J, Kashdan TB, Hurling R. Using personal and psychological strengths leads to increases in well-being over time: A longitudinal study and the development of the strengths use questionnaire. Personality and Individual Differences. 2011;50(1):15-9.

69. Meyer TJ, Miller ML, Metzger RL, Borkovec TD. Development and validation of the Penn State Worry Questionnaire. Behaviour research and therapy. 1990;28(6):487-95, PMID: 2076086.

70. Sherbourne CD, Stewart AL. The MOS social support survey. Social science \& medicine. 1991;32(6):705-14, PMID: 2035047.

71. Shakespeare-Finch J, Obst PL. The development of the 2-way social support scale: a measure of giving and receiving emotional and instrumental support. Journal of personality assessment. 2011;93(5):483-90, PMID: 21859288.

72. Lovibond PF, Lovibond SH. The structure of negative emotional states: Comparison of the Depression Anxiety Stress Scales (DASS) with the Beck Depression and Anxiety Inventories. Behaviour Research and Therapy. 1995;33(3):335-43, PMID: 7726811. 73. Kirakowski J, Claridge N, Whitehand R, editors. Human centered measures of success in web site design. Proceedings of the Fourth Conference on Human Factors \& the Web; 1998.

74. Moore A, Parr G, Logan M, Neely H, Roesner D, Dürer U. Developing a European internet and kiosk-based health information system. Journal of medical Internet research. 2001;3(e6, PMID: 11720948).

75. Thoma V, White EP. In two minds about usability? rationality and intuition in usability evaluations. Human-Computer Interaction: Springer; 2011. p. 544-7.

76. Birmaher B. Improving remission and preventing relapse in youths with major depression. American Journal of Psychiatry. 2014.

77. Kennard BD, Silva SG, Tonev S, Rohde P, Hughes JL, Vitiello B, et al. Remission and recovery in the Treatment for Adolescents with Depression Study (TADS): acute and long-term outcomes. Journal of the American Academy of Child \& Adolescent Psychiatry. 2009;48(2):186-95. 
78. Kennard B, Silva S, Vitiello B, Curry J, Kratochvil C, Simons A, et al. Remission and residual symptoms after short-term treatment in the Treatment of Adolescents with Depression Study (TADS). Journal of the American Academy of Child \& Adolescent Psychiatry. 2006;45(12):1404-11.

79. Moreno MA, Jelenchick LA, Egan KG, Cox E, Young H, Gannon KE, et al. Feeling bad on facebook: Depression disclosures by college students on a social networking site. Depression and Anxiety. 2011;28(6):447-55, PMID: 21400639.

80. Kramer AD, Guillory JE, Hancock JT. Experimental evidence of massive-scale emotional contagion through social networks. Proceedings of the National Academy of Sciences. 2014;111(24):8788-90, PMID: 24889601.

81. Manicavasagar V, Horswood D, Burckhardt R, Lum A, Hadzi-Pavlovic D, Parker G. Feasibility and Effectiveness of a Web-Based Positive Psychology Program for Youth Mental Health: Randomized Controlled Trial. Journal of Medical Internet Research.

2014;16(6):e140, PMID: 24901900.

82. van der Zanden R, Kramer J, Gerrits R, Cuijpers P. Effectiveness of an online group course for depression in adolescents and young adults: a randomized trial. Journal of Medical Internet Research. 2012;14(3):e86, PMID: 22677437.

83. Hoek W, Schuurmans J, Koot HM, Cuijpers P. Effects of Internet-Based Guided SelfHelp Problem-Solving Therapy for Adolescents with Depression and Anxiety: A

Randomized Controlled Trial. Plos One. 2012;7(8):e43485, PMID: 22952691.

84. Alvarez-Jimenez M, Alcazar-Corcoles M, Gonzalez-Blanch C, Bendall S, McGorry P, Gleeson J. Online, social media and mobile technologies for psychosis treatment: a systematic review on novel user-led interventions. Schizophrenia Research. 2014;156(1):96106, PMID: 24746468.

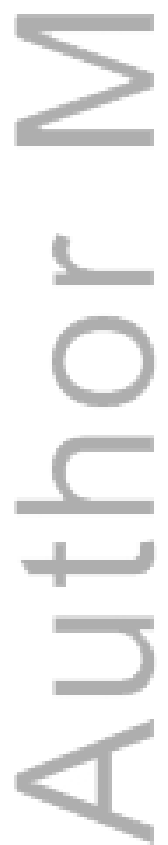

This article is protected by copyright. All rights reserved. 
Table 1: Frequency of Rebound therapy module usage

\begin{tabular}{|c|c|c|}
\hline $\begin{array}{l}\text { Therapy component } \\
\text { (Step) }\end{array}$ & Description & $\mathrm{n}(\%)^{\mathrm{a}}$ \\
\hline How Rebound works & $\begin{array}{l}\text { This module provided users an overview of the key features of } \\
\text { Rebound including the social networking, private messaging, the role } \\
\text { of peer and expert moderators, the Talk It Out function and general } \\
\text { privacy information. }\end{array}$ & $42(100)$ \\
\hline Find your strengths & $\begin{array}{l}\text { In this module users were introduced with the concept of personal } \\
\text { strengths. The modules used an interactive online card sort game where } \\
\text { users identify their 'signature' strengths. Assessment of strengths was } \\
\text { informed by the positive psychology framework. }{ }^{(58,59)}\end{array}$ & $42(100)$ \\
\hline How to flourish & $\begin{array}{l}\text { In this module users were encouraged to put their identified strengths } \\
\text { into practice. Users reflected and interacted with each other regarding } \\
\text { their future goals, engaging with meaningful activities and overcoming } \\
\text { barriers. }^{(60)}\end{array}$ & $30(71)$ \\
\hline Everybody & $\begin{array}{l}\text { This module provided users with psychoeducation regarding } \\
\text { precipitants and perpetuating factors related to depression, and factors } \\
\text { that contribute to resilience and recovery. }\end{array}$ & $14(33)$ \\
\hline Small is & $\begin{array}{l}\text { This module focused on behaviour change. Users were provided with a } \\
\text { structured goal setting framework. Users were encouraged to } \\
\text { deconstruct seemingly unsurmountable tasks into achievable elements, } \\
\text { and helped to notice and enjoy the process of behaviour change. }\end{array}$ & $13(31)$ \\
\hline $\begin{array}{l}\text { Can a pencil make } \\
\text { you happy }\end{array}$ & $\begin{array}{l}\text { This module introduced the construct of behavioural experiments }{ }^{(53)} \\
\text { used throughout Rebound. In this experiment users were encouraged to } \\
\text { interact with others (i.e., sharing positive experiences) and break their } \\
\text { usual routine, through a basic task eliciting positive affect. }^{(61)}\end{array}$ & $10(24)$ \\
\hline Relaxation skills & $\begin{array}{l}\text { This module aimed to up-skill users in progressive muscle relaxation } \\
\text { (PMR) techniques and relaxation breathing. Users were able to } \\
\text { download purpose made audio tracks teaching PMR and breathing }\end{array}$ & $9(21)$ \\
\hline
\end{tabular}




\begin{tabular}{|l|l|l|}
\hline Compassion for & techniques. & This module integrated self-compassion techniques ${ }^{(62)}$ for managing \\
others & $\begin{array}{l}\text { difficult emotions and situations. Purpose made audio tracks are } \\
\text { available for users to download. }\end{array}$ & $9(21)$ \\
\hline Savouring & $\begin{array}{l}\text { This modules drew on the positive psychology technique of } \\
\text { to help them make the most of positive experiences. }\end{array}$ & 8 (19) \\
\hline Rumination & $\begin{array}{l}\text { This module assisted users to identify helpful and unhelpful ruminative } \\
\text { thought process, and provided examples of ways to break these cycles. }\end{array}$ & $6(14)$ \\
& $\begin{array}{l}\text { The modules adopted Watkins }{ }^{(64)} \text { model of managing unconstructive } \\
\text { repetitive thought. }\end{array}$ & \\
\hline
\end{tabular}

${ }^{a}$ Percentage of participants who undertook the module 
Table 2: Logins and individual usage of the main components of the Rebound intervention $(n=42)$.

\begin{tabular}{lcccc}
\hline Site component & Total & M & SD & Mdn \\
\hline Logins & 3,034 & 70.6 & 123.3 & 16.5 \\
Social networking - posts & 751 & 17.9 & 24.0 & 9.5 \\
\hline Social networking - likes & 819 & 19.5 & 39.7 & 3.5 \\
\hline Social networking - comments & 576 & 13.7 & 22.7 & 4.0 \\
Therapy modules (Steps) & 195 & 4.6 & 4.5 & 4.0 \\
\hline Actions & 158 & 3.8 & 5.3 & 2.0
\end{tabular}

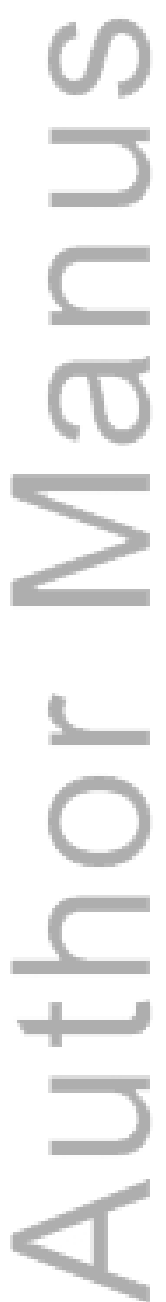

This article is protected by copyright. All rights reserved. 
Table 3: Participant impressions of the Rebound intervention $(n=39)$.

\begin{tabular}{|c|c|c|c|c|c|}
\hline Rebound experience & M & SD & Mdn & Range & $\mathrm{n}(\%)^{\mathrm{a}}$ \\
\hline \multicolumn{6}{|l|}{ General } \\
\hline I felt safe on Rebound ${ }^{b}$ & 4.7 & 0.6 & 5.0 & $3-5$ & $37(100)$ \\
\hline I felt my profile was confidential ${ }^{\mathrm{c}}$ & 4.5 & 0.7 & 5.0 & $2-5$ & $34(91.9)$ \\
\hline Rebound was a positive experience ${ }^{b}$ & 4.2 & 0.7 & 4.0 & $3-5$ & $38(100)$ \\
\hline Rebound was helpful ${ }^{\mathrm{b}}$ & 3.6 & 1.2 & 4.0 & $1-5$ & $32(84.2)$ \\
\hline Rebound helped me feel more socially connected ${ }^{\mathrm{b}}$ & 3.5 & 1.2 & 4.0 & $1-5$ & $35(94.6)$ \\
\hline Rebound helped me control my mood ${ }^{b}$ & 3.1 & 1.0 & 3.0 & $1-5$ & $26(70.3)$ \\
\hline The moderators encourage open discussion ${ }^{\mathrm{d}}$ & 6.0 & 1.1 & 6.0 & $4-7$ & $38(100)$ \\
\hline I felt that the moderators accepted me ${ }^{\mathrm{d}}$ & 5.8 & 1.1 & 6.0 & $4-7$ & $38(100)$ \\
\hline I felt the moderators provided me with choices ${ }^{\mathrm{d}}$ & 5.5 & 1.1 & 6.0 & $4-7$ & $38(100)$ \\
\hline The moderators listen to how I would like use Rebound ${ }^{\mathrm{d}}$ & 5.6 & 1.1 & 5.5 & $4-7$ & $38(100)$ \\
\hline
\end{tabular}

\footnotetext{
${ }^{a}$ Number of cases responding in the positive range, based on complete responses, denominator of $\%$ varies based on missing data.

${ }^{\mathrm{b}}$ Items rated from $1=$ not at all; 5 = very much.

citems rated from $1=$ not at all confidential; $5=$ very confidential

${ }^{\mathrm{d}}$ Items rated from 1 = strongly disagree; 7 = strongly agree.
} 
Table 4: Change between baseline and 12-week follow-up for clinical outcome variables

\begin{tabular}{lcccccccc}
\hline Measure & \multicolumn{3}{c}{ Baseline } & \multicolumn{3}{c}{ 12-week follow-up } & \multicolumn{2}{c}{ Statistic } \\
\cline { 2 - 9 } & $\mathbf{\alpha}$ & M & SD & $\boldsymbol{\alpha}$ & M & SD & $\boldsymbol{p}$ & $\boldsymbol{d}$ \\
\hline MADRS & .73 & 16.2 & 6.9 & .93 & 12.1 & 11.4 & $\mathbf{. 0 1 4}$ & 0.45 \\
SOFAS & - & 67.3 & 12.2 & - & 68.1 & 10.7 & .716 & 0.03 \\
Strengths use & .96 & 4.4 & 1.2 & .96 & 4.7 & 1.3 & $\mathbf{. 0 8 8}$ & 0.29 \\
Social connectedness & .96 & 3.9 & 0.9 & .95 & 3.9 & 0.9 & .711 & 0.06 \\
Social support & .94 & 3.7 & 0.9 & .94 & 3.8 & 0.9 & .470 & 0.08 \\
Worry & .76 & 3.5 & 0.8 & .81 & 3.6 & 0.9 & .391 & 0.05 \\
Anxiety & .79 & 6.1 & 4.7 & .89 & 6.8 & 6.0 & .184 & 0.13 \\
\hline
\end{tabular}

Note. Refer to reference list for full information on outcome measures MADRS ${ }^{(66)}$ SOFAS, ${ }^{(67)}$ Strengths use ${ }^{(68)}$ Social connectedness, ${ }^{(70)}$ Social support, ${ }^{(71)}$ Worry,${ }^{(69)}$ Anxiety. ${ }^{(72)}$ 


\section{University Library}

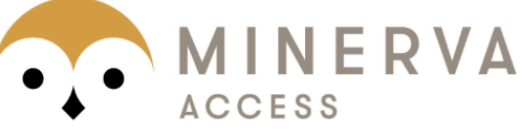

A gateway to Melbourne's research publications

Minerva Access is the Institutional Repository of The University of Melbourne

\section{Author/s:}

Rice, S;Gleeson, J;Davey, C;Hetrick, S;Parker, A;Lederman, R;Wadley, G;Murray, G;Herrman, H;Chambers, R;Russon, P;Miles, C;D'Alfonso, S;Thurley, M;Chinnery, G;Gilbertson, T;Eleftheriadis, D;Barlow, E;Cagliarini, D;Toh, J-W;McAlpine, S;Koval, P;Bendall, S;Jansen, JE;Hamilton, M;McGorry, P;Alvarez-Jimenez, M

Title:

Moderated online social therapy for depression relapse prevention in young people: pilot study of a "next generation' online intervention

Date:

2018-08-01

\section{Citation:}

Rice, S., Gleeson, J., Davey, C., Hetrick, S., Parker, A., Lederman, R., Wadley, G., Murray, G., Herrman, H., Chambers, R., Russon, P., Miles, C., D'Alfonso, S., Thurley, M., Chinnery, G., Gilbertson, T., Eleftheriadis, D., Barlow, E., Cagliarini, D. ,... Alvarez-Jimenez, M. (2018). Moderated online social therapy for depression relapse prevention in young people: pilot study of a "next generation' online intervention. EARLY INTERVENTION IN PSYCHIATRY, 12 (4), pp.613-625. https://doi.org/10.1111/eip.12354.

Persistent Link:

http://hdl.handle.net/11343/291422 